\title{
Sanal Zorbalıkla Baş Etme Ölçeği: Geçerlilik ve Güvenirlik Çalışmasi*
}

\author{
Mustafa KOÇ** \\ Furkan AYDIN***** \\ Senem ÇOLAK ${ }^{* * *+* *+* * *}$
}

Tuncay AYAS ${ }^{* * * *}$

Erol UĞUR $R^{* * * * * * *}$

Öz

Bilgi ve iletişim teknolojileri öğrenciler tarafından amacı dışında birbirlerine zarar vermek amacıyla ortaya çıkan sanal zorbalık olayları günümüzde önemli bir sorun haline geldiği görülmektedir. Okullarda öğrenciler arasında yaşanan bu olaylar öğrencileri akademik, psikolojik ve sosyal açıdan olumsuz şekilde etkilemektedir. Öğrenciler sanal zorbalık olaylarıyla baş edebilmek için farklı yöntem ve teknikler kullanabilmektedirler. Okullarda yaşanan bu tür olaylarla öğrencilerin nasıl baş etiklerini tespit etmek amacıyla bu ölçek geliştirme çalışması yapılmıştır. Araştırmada veriler açımlayıcı ve doğrulayıcı faktör çalışmalar için farklı liselerde eğitim öğretim faaliyetlerini sürdüren iki gruptan toplanmıştır. Açımlayıcı faktör için veriler Sakarya ili merkezinde yer alan farklı liselerde öğrenim gören 264 öğrencinin 140'1 dokuzuncu sınıf öğrencisinden (\%53) ve 124'ü (\%47) on birinci sınıf öğrencilerinden oluşmuştur. Katılımcılardan 129'u (\%48,9) kız, 135'i (\%51,1) erkektir. İkinci çalışmada doğrulayıcı faktör analizi için Sakarya ili merkezinde yer alan farklı liselerde öğrenim gören 277 öğrenciden veriler toplanmıştır. Öğrencilerin 135'i (\%48.7) dokuzuncu sınıf ve 142'si (\%51.3) onuncu sınıf öğrencisidir. Bu katılımcılardan 136'sı (\%49.1) kız, 141'i (\%50.9) erkektir. Öğrenciler 15 ile 18 yaş arasındadır. Ölçek geliştirme sürecinde öncelikle sanal zorbalıkla baş etmeyle ilgili alan yazın incelenerek madde havuzu oluşturulmuştur. Oluşan madde havuzuyla ilgili uzman görüşleri doğrultusunda ölçekte gerekli düzeltmeler yapıldıktan sonra ölçek hedef kitleye uygulanarak ölçeğin faktöriyel ve yapı geçerlikleri ile güvenirlik analizleri yapılmıştır. Ölçeğin analizlerinde faktöriyel geçerlik için açımlayıcı ve doğrulayıcı faktör analizi, yapı geçerliği için yakınsama ve ayırt edici geçerlik ve güvenirlik içinse Cronbach alfa iç tutarlılık ve kompozit güvenirlik katsayılarına bakılmıştır. Yapılan bu işlemler sonucunda 19 madde ve 4 faktörden oluşan geçerli ve güvenilir bir sanal zorbalıkla baş etme ölçeği elde edilmiştir

Anahtar Kelimeler: Sanal zorbalık; baş etme; ölçek geliştirme, lise.

\footnotetext{
* Bu çalışma TÜBİTAK tarafından desteklenen 115K44 nolu proje kapsamında gerçekleştirilmiştir.

** Doç. Dr., Sakarya Üniversitesi, Psikolojik Danışma ve Rehberlik Bölümü, mkoc@sakarya.edu.tr

*** Doç. Dr., Sakarya Üniversitesi, Bilgisayar ve Öğretim Teknolojileri Bölümü, mhorzum@sakarya.edu.tr

**** Doç. Dr., Sakarya Üniversitesi, Psikolojik Danışma ve Rehberlik Bölümü, tayas@sakarya.edu.tr

***** Sakarya Üniversitesi, furkanaydin@live.com

****** Sakarya Üniverstesi Eğitim Bilimleri Enstitüsü, Doktora Öğrencisi, ahmetozbay@hotmail.com

******** Arş. Gör., Sakarya Üniversitesi, Psikolojik Danışma ve Rehberlik Bölümü, eugur@sakarya.edu.tr

********* Dr., menes83s@gmail.com
} 


\title{
Coping With Cyberbullying Scale: Study of Reliability and
}

\author{
Validity
}

\begin{abstract}
It is seen that cyberbullying and cyber victimization have become important problems nowadays because students misuse the information and communication technologies to harm each other. Such events experienced between students at the school have negative effects on academic, psychological and social performance of students. Students may use different methods and techniques to cope with cyberbullying. This study is designed to develop a scale for identifying the coping strategies of students. Confirmatory factor analysis and exploratory factor analysis were applied to the data in the research. 264 high school students from Sakarya participated in the study for exploratory factor analysis. 140 of them were attending at the ninth grade (53\%) and 14 of them were the $11^{\text {th }}$-grade students. 129 of the participants $(48,9 \%)$ were female and 135 of them $(51,1 \%)$ were male. 277 high school students from Sakarya participated in the second study for confirmatory factor analysis. $135(48.7 \%)$ of the students were studying in the ninth grade while $142(51.3 \%)$ of them were in $10^{\text {th }}$ grade. $136(49.1 \%)$ of the students were female, $141(50.9 \%)$ of them were male. The ages of the students varied between 15 and 18. During the process of the scale development, first of all, the literature related to the strategies of coping with cyber bullying was reviewed and an item pool was created. Scale was corrected according to expert views, and then, construct validity, factor analysis and reliability analysis were applied. Confirmatory factor analysis and exploratory factor analysis were applied for factorial validity. Moreover, convergence was used for construct validity and Cronbach Alpha and composite reliability coefficient were utilized for distinguishing validity and reliability. Finally, a valid and reliable scale of coping with cyber bullying that has 19 items and 4 factors was developed.
\end{abstract}

Keywords: Cyber bullying, coping, scale development, high school.

\section{GíRiş}

Öğrenciler arasında okullarda yaşanan saldırganlık olayları bilgi ve iletişim teknolojilerinin kullanılmasıyla birlikte farklı bir boyut kazanmıştır. Bireylerin teknolojiyi kullanarak birbirlerine zarar verici davranışlarda bulunmasina sanal zorbalık denilmektedir. Belsey (2008) sanal zorbalığı, bir birey veya grubun bilgi ve iletişim teknolojilerini diğer bireylere zarar vermek amaciyla kötü niyetle ve tekrarlayan biçimde kullanması olarak tanımlamaktadır. Sanal zorbalığın çeşitli bilişim ve iletişim araçlarının kullanımı ile meydana geldiği söylenebilir. Siber zorbalık davranışlarının, SMS yoluyla, cep telefonu kamerası aracilığıyla video ve resim çekilerek, cep telefonuyla diğer bireyleri rahatsız ederek, sohbet odalarında, e-posta yoluyla, anlık mesajlaşma sırasında veya web siteleri aracılı̆̆ıyla meydana geldiği belirtilmektedir ( Smith, Mahdavi, Carvalho ve Tippett, 2006).
Sanal zorbalığın dünya çapında bilgi ve iletişim teknolojilerinin yaygın bir şekilde kullanılmaya başlanmasıyla birlikte ve bireyler arasında ki iletişim süreçlerinde yaşanan olumsuzluklara paralele olarak yaygınlaştığı bilinmektedir. Farklı ülkelerde yapılan bazı çalışmalar incelendiğinde (Arıcak, 2009; Ayas, 2011; Ayas ve Horzum, 2012; Dredge, John ve Garcia, 2014; Eroğlu, 2011; Kowalski ve Limber, 2007; Li, 2006; Peker, Eroğlu ve Ada, 2012; Raskauskas ve Stoltz 2007; Stys, 2004; Willard, 2005; Wolak, Mitchell ve Finkelhor, 2007) sanal zorbalık olaylarının okullarda önemli bir sorun olduğu görülmektedir.

Sanal zorbalık olayları bireyleri olumsuz şekilde etkilemektedir. Beran ve Li (2007) sanal zorbalığın ve sanal mağduriyetin gençlerin psikososyal gelişimi ve akademik başarısı üzerinde olumsuz etkileri olduğunu savunmaktadırlar. Şahin, Aydın ve Sarı (2012) da, özellikle akranlardan gelen sanal zorbaca davranışların ergenlerin bireysel, sosyal, 
duygusal ve psikolojik gelişimine zarar verdiğini söylemektedirler. Burgess-Proctor ve diğerleri (2010) sanal zorbalığa maruz kalan kızların \% 35 'inin sinirlendiğini, \% 30' unun üzüldügüünü ve $\%$ 41'inin sanal zorbalıktan dolayı hayal kırıklığı yaşadığını gözlemişlerdir. Ayrıca, sanal zorbalık yapmayan ve sanal zorbalığa maruz kalmayan bireylerin sanal zorba ve sanal mağdurlardan daha az psikiyatrik belirti gösterdiği görülmektedir (Arıcak, 2009). Hinduja ve Patchin (2008) da bu bulgulara paralel olarak, sanal mağduriyetin stres yaratıcı yaşam koşullarının da etkisiyle bireylerin intihar etmesine yol açabileceğini savunmaktadır. Batmaz ve Ayas (2013) yaptıkları çalışmada sanal zorbalık düzeyi ile öfke düşmanlık arasında bir ilişkinin olduğu ve Ayas (2014) tarafından yapılan çalışmada ise sanal zorbalığa maruz kalma düzeyleri ile depresyon ve anksiyete arasında pozitif ilişki olduğu belirlenmiştir..

Sanal zorbalığın bireylerde oluşturduğu olumsuz etkilerinden korunmak ve vereceği muhtemel zararları önlemek adına bazı çalışmalar yürütülmüştür. Worthen (2007), okullarda sanal zorbalığın vereceği zararlardan korunmak adına önleme ve müdahale çalışmaları yapılması gerektiğini savunmaktadır. Problemin ortaya çıkmasını beklemek yerine problem ortaya çıkmadan önlemeye yönelik çalışmalar yapmak, yaşanacak olumsuzlukların daha az bir etki oluşturmasına neden olacaktır. Önlemenin, hem duygusal hem de maddi açıdan olumsuz olaylar veya davranışlar meydana geldikten sonra harekete geçmekten daha faydalı ve karlı olduğu belirtilmektedir. Sanal zorbalığın özellikleri ve etkenleri ile ilgili bilgi sahibi olmak önleme ve müdahale programları oluşturmada yararlı olacaktır. Ayrıca, bu konularda çalışan araştırmacıların elde ettikleri verileri de okul çalışanları ve yöneticileri ile paylaşmaları faydalı olacaktır (Ayas ve Horzum, 2011). Benzer şekilde Li (2006) de, okullarda sanal zorbalık konusunda yapılacak önleme ve müdahale çalışmalarına okul, aile ve toplumun ortaklaşa katılımlarının çok önemli olduğunu belirtmektedir. Bu konuda yapılmış en kapsamlı programın Olweus tarafından geliştirilen zorbalığı önleme programı olduğu bilinmektedir (Olweus vd.,1999). Bu programda zorbalığa karşı farkındalık oluşturmak, öğrencilere bu konuda bilgi vermek, onlara gözlemci olmak, zorbalık karşıtı kuralları açık bir şekilde ifade etmek bu kurallara uyulmadığında oluşacak olumsuz sonuçları ortaya koymak, olumlu yetişkin rol modelleri kullanmak gibi ayrıntılara yer verildiği dikkat çekmektedir. Willard (2005), bu tür programların örnek alınarak okullarda sanal zorbalığ 1 önleme ve müdahale programları geliştirilebileceğini savunmaktadır. Yeni oluşturulacak anti şiddet politikalarında okulların; öğrencilerin interneti ve mobil teknolojileri şiddet amaçlı kullanmalarını yasaklamaya, bu yasağa uymadıkları takdirde kendileri için ciddi sonuçlar doğurabileceğini ifade etmeye cesaretlendirilmesi gerektiği düşünülmektedir. Willard (2005) okullarda uygulanacak sanal zorbalığa müdahale programında; sınıf içi müdahaleler, bireysel müdahaleler, öğrencilerle çalışma, mağduru destekleme, zorba ile çalışma, ailenin katılımı, toplumun müdahalesi gibi ayrıntılı konuların yer alması gerektiğini savunmaktadır. Ayrıca, okullarda bilgisayar ve internetin güvenilir ve sorumlu bir şekilde kullanılabilmesi için öğrencilere rehberlik etmekle de görevli olduğu belirtilmektedir. Öğrencilerin internet ortamında özel, kişisel bilgilerini koruma konusunda bilgilendirilmesi ve karşılaşabilecekleri risklerle ilgili uyarılması gerektiği savunulmaktadır (Bryce ve Klong, 2009).

Wrighta, Burnhamb, Christopherc ve Heatherd (2009) sanal zorbalık olaylarını önlemek için öncelikle bu tür olaylarla ilgili farkındalı̆̆ 1 geliştirmek gerektiğini ifade etmektedirler. $\mathrm{Bu}$ yönüyle farkındalık oluşturmada öncelikle neyin sanal zorbalık olduğu neyin olmadığına yönelik bilgi verilmesi gerektiği ardından bu tür olaylarla karşılaştı̆̆ında nasıl hareket etmesi gerektiği ile ilgili bilgi verilmelidir. Sanal zorbalık olaylarının önlenmesindeki son adım bu tür olaylarla karşılaşan bireylere uygun baş etme stratejilerinin kazandırılması gerektiği belirtilmiştir. 
Ergenlerin özellikle internet üzerinden karşılaştıkları sanal zorbalık sorunlarıyla etkili bir şekilde nasıl baş edebilecekleri konusunda yeterli tecrübeye henüz sahip olmadikları gözlemlenmektedir. Juvonen ve Gross (2008) ergenlerin internette karşılaştıkları zorbalığı önlemek amacıyla farklı yöntemler kullandıkları görülmüştür. En çok kullanılan yöntemin özel ekran şifresini yok etmek olduğu tespit edilmiştir. Araştırmaya katılan bireylerin \%33'ünün ekranda kullandığı şifreyi arkadaş listelerinde yer alan kişilerin birçoğuna vermediği, \%26'sının ekran şifresini değiştirdiği, \%25'inin ise tacizcisini ikaz ettiği saptanmıştır. Yapılan çalışmalarda, bazı gençlerin sanal zorbalıktan korunmak için neler yapılması gerektiğinden haberdar oldukları, teknolojik bilgilerini kullanarak ya da tehlikeli sanal ortamlardan kaçınarak bu durumla baş ettikleri de elde edilen bulgular arasında yer almaktadir. Patchin ve Hinduja (2006) ya göre bireylerin sanal zorbalıkla baş etmek için en çok kullandıkları yöntemleri; yaşanan bu olayları arkadaşları, aileleri ve bir yetişkinle paylaştıkları bununla birlikte sanal zorbalık yapan kişiye bu davranışlarından vaz geçmelerini istedikleri ve sanal ortamı terk etme yöneliminde olduğu görülmektedir.

Ülkemizde sanal zorbalık konusunda çalışmalar 2000 li yılların başında yapılmaya başlandı ğı için bu konuyla ilgili ölçek çalışmalarının da yeni yapılmaya başlandığı görülmektedir. Yapılan bu ölçek çalışmaları incelendiğinde sanal zorbalık olaylarının farklı şekillerde değerlendiren ölçekler olduğu görülmektedir. Ayas ve Horzum (2010) ilköğretim ikinci kademe öğrencileri arasında görülen sanal zorbaca davranışları "sanal zorba" ve "sanal kurban" olarak ölçebilecek geçerli ve güvenilir bir ölçek geliştirme çalışması yapmışlardır. Arıcak, Kınay ve Tanrıkulu (2012) tarafından geliştirilen ölçek, önceki ölçek geliştirme çalışmalarından farklı olarak daha geniş bir yaş grubunu (11-18) kapsamaktadır. Bu ölçek ile ergenlerin sanal zorbalık davranışlarını ölçmek amaçlanmaktadır. Benzer şekilde, Uysal, Duman, Yazıcı ve Şahin (2014) tarafından geliştirilen Siber Zorbalığa
İlişkin Duyarlılık Ölçeği'nin geçerli ve güvenilir bir ölçme aracı olduğu görülmektedir. Gezgin ve Çuhadar (2012), Bilgisayar ve Öğretim Teknolojileri Eğitimi Bölümü öğrencilerinin sanal zorbalığa ilişkin duyarlılık düzeylerini belirledikleri ve siber zorbalığa ilişkin duyarlılık düzeylerini çeşitli değişkenlere göre inceledikleri çalışmalarında Siber Zorbalığa ilişkin Duyarlılık Ölçeği'ni kullanmışlardır. Ayas, Aydın ve Horzum, (2015) tarafından geliştirilen sanal zorbalık farkındalık ölçeği olduğu görülmektedir.

Yapılan araştırmalar sanal zorbalık olaylarının bilgi ve iletişim teknolojilerinin bireyler tarafindan bir birlerine zarar vermek amaciyla kullanılmaya başlanmasıyla birlikte arttığını ortaya koymaktadır. Sanal zorbalık olaylarının önlenebilmesi, gençlerin sanal zorbalığın farkına varması ve bu tür olaylarla uygun baş etme stratejileri kullanmasına bağlı olduğu dikkate alındığında bireylerin ne tür baş etme stratejileri kullandıkları belirlenmesi ve uyguladıkları uygun olmayan baş etme stratejilerinden vazgeçerek amaca uygun baş etme stratejilerini kullanmalarının bireylere öğretilmesi gerekmektedir. Bireylere uygun baş etme stratejilerini öğretebilmek için öncelikle bireylerin uyguladıkları baş etme stratejilerini belirlemek gerekmektedir. Bireylerin kullandıkları baş etme stratejilerini belirlemek amacıyla böyle bir çalışmaya ihtiyaç duyulmuştur. $\mathrm{Bu}$ açıdan yapılan bu çalışmanın alan yazına katkı sunacağı düşünülmektedir.

\section{YÖNTEM}

\subsection{Model}

Araştırma ölçek geliştirme çalışmasıdır. Ölçek geliştirme çalışmalarında öncelikle literatür taraması ile madde havuzu oluşturulur. Oluşturulan havuz ile ilgili görünüş ve kapsam geçerliği için uzman görüşü alınarak ölçeğin pilot uygulaması yapılır. Pilot uygulama ve uzman görüşleri doğrultusunda ölçeğin düzeltmeleri yapılır. Ardından hedef kitleye ölçek uygulanarak faktöriyel ve yapı geçerliği ile 
güvenirlik çalışmaları gerçekleştirilir. $\mathrm{Bu}$ çalışmada da benzer adımlar izlenmiştir.

\subsection{Katılımcilar}

Sanal zorbalıkla baş etme stratejileri ölçeğinin geliştirilmesinde araştırmanın katılımcıları iki farklı çalışma için iki ayrı grup olarak ele alınmıştır. İlk çalışmada açımlayıcı faktör analizi için Sakarya ili merkezinde yer alan farklı liselerde öğrenim gören 264 öğrencinin 140'1 dokuzuncu sınıf öğrencisinden (\%53) ve 124'ü (\%47) on birinci sinıf öğrencilerinden oluşmuştur. Katılımcılardan 129'u (\%48,9) kız, 135'i (\%51,1) erkektir. İkinci çalışmada doğrulayıcı faktör analizi için Sakarya ili merkezinde yer alan farklı liselerde öğrenim gören 277 öğrencinin 135'i (\%48.7) dokuzuncu sinıf ve 142'si (\%51.3) onuncu sinıf öğrencisinden oluşmuştur. Bu katılımcılardan 136'sı (\%49.1) kız, 141'i (\%50.9) erkektir. Öğrenciler 15 ile 18 yaş arasındadir.

\section{3 Ölçek}

Sanal zorbalık baş etme stratejileri ölçeği araştırmacılar tarafından geliştirilmiştir. Ölçek geliştirilirken araştırmacılar tarafından öncelikle alan yazın taraması yaparak sanal zorbalık ile başa çıkma stratejilerine uygun olabilecek maddeler çıkarılmış ve gerekli durumlarda bazı maddeler sanal zorbalık ile başa etme stratejileri ölçeği için uygun şekilde değiştirilmiştir. Ardından alan yazında yer alan Peker, Özhan ve Eroğlu (2015), Raskauskas ve Huynh (2015), Broll (2014), Frisén, Berne ve Marin (2014), Völlink, Bolman, Dehue ve Jacobs (2013), O'Brien ve Moules (2013), Wachs, Wolf ve Pan (2012) çalışmaları incelenerek uygun olan bazı maddeler madde havuzuna değiştirilerek ve ya doğrudan alınmıştır. Araştırmacılar tarafından oluşturulan madde havuzunda 20 madde yer almıştır. Madde havuzunun katılım düzeyi için 5'li Likert tipi dereceleme seçilmiş ve dereceleme "kesinlikle katılıyorum (5), katılıyorum (4), kararsızım (3), Katılmıyorum (2) ve kesinlikle katılmıyorum (1)" şeklinde belirlenmiştir. Bu işlemlerin ardından geçerlik güvenirlik çalışmalarına geçilmiştir.

\section{4 İşlemler}

Ölçeğin geçerlik çalışmaları için kapsam, görünüş, faktöriyel ve yapı geçerliğine bakılmıştır. Kapsam ve görünüş geçerliği için ölçeğin sunulacağı uzmanlar olarak bilgisayar ve öğretim teknolojileri, psikolojik danışma ve rehberlik alanından akademisyenler seçilmiştir. 6 uzman maddeleri incelemiş ve bir maddenin çıkarılmasını, 7 maddedeki ifadelerin değiştirilmesini istemişlerdir. Uzman incelemesinde belirtilen tüm düzeltmeler yapılmıştır. Ölçeğin kapsam ve görünüş geçerliğinden sonraki hali toplam 19 maddeden oluşmuştur.

$\mathrm{Bu}$ işlemlerden sonra ölçeğin faktöriyel ve yapı geçerliği ve güvenirlik çalışmalarına geçilmiştir. Ölçeğin faktöriyel geçerliğinde öncelikle açımlayıcı faktör analizi (AFA) ile yapısı incelenmiş ve bu yapıyı doğrulamak içinse doğrulayıcı faktör analizi (DFA) uygulanmıştır. Ölçeğin yapı geçerliği için yakınsama ve ayırt edici geçerlik uygulanmıştır. Yakınsama geçerliğinde ölçeğin faktör yüklerinin ve ortalama açıklanan varyans (OAV) değerlerinin 0,50 değerine eşit ve büyük olup olmadığ1 incelenmiştir. Ayırt edici geçerlik içinse faktörlerin OAV değerlerinin kareköklerinin faktörler arasındaki korelasyon değerinden küçük olup olmadığına bakılarak karar verilmiştir.

Ölçeğin geçerlik güvenirlik çalışmaları için ölçek toplam 600 öğrenciye dağıtılmış ve bunlardan 550'si geri dönmüştür. Bu ölçeklerden 9'u tek bir katılma derecesi işaretlendiği için araştırmadan çıkarılmıştır. Sonuçta toplam 541 öğrenci verileri üzerinden işlem yapılmıştır. İki ayrı veri setinde AFA ve DFA analizleri yapılmıştır. AFA ve korelasyon için SPSS 13.0, DFA için Lisrel 8.54 paket programı kullanılmıştır.

\section{BULGULAR}

Bulguların sunumunda öncelikle faktöriyel geçerlik için sırasıyla AFA ve DFA analizlerine yönelik bulgular ile başlanmıştır. Ardından yapı geçerliği için yakınsama ve ayırt edici geçerliğine 
yönelik bulgular aktarılmıştır. Geçerlik bulgularının ardından güvenirliğe yönelik bulgular sunulmuştur.

\subsection{Açımlayıcı Faktör Analizine Yönelik Bulgular}

AFA, 19 maddeye verilen cevaplar üzerinden gerçekleştirilmiştir. Analizde öncelikle KaiserMayer-Olkin (KMO) ve Bartlett'in Küresellik Testi'ne testi sonuçlarına bakılmıştır. AFA sonucunda KMO değeri .792 ve Küresellik Testi ise $\chi 2=1476,786, p .=.000^{\prime}$ dir. Bu sonuçlara göre toplanan verilerle AFA yapılabileceği görülmüştür. Faktör analizinde 19 madde ile temel bileşenler analizi gerçekleştirilmiştir. 19 madde ile gerçekleştirilen analizde ölçeğin maddelerinin dört faktöre dağıldığ 1 belirlenmiştir. AFA'dan elde edilen saçılım grafiğine bakıldığında ölçekteki faktör sayısı net olarak görülebilmektedir.

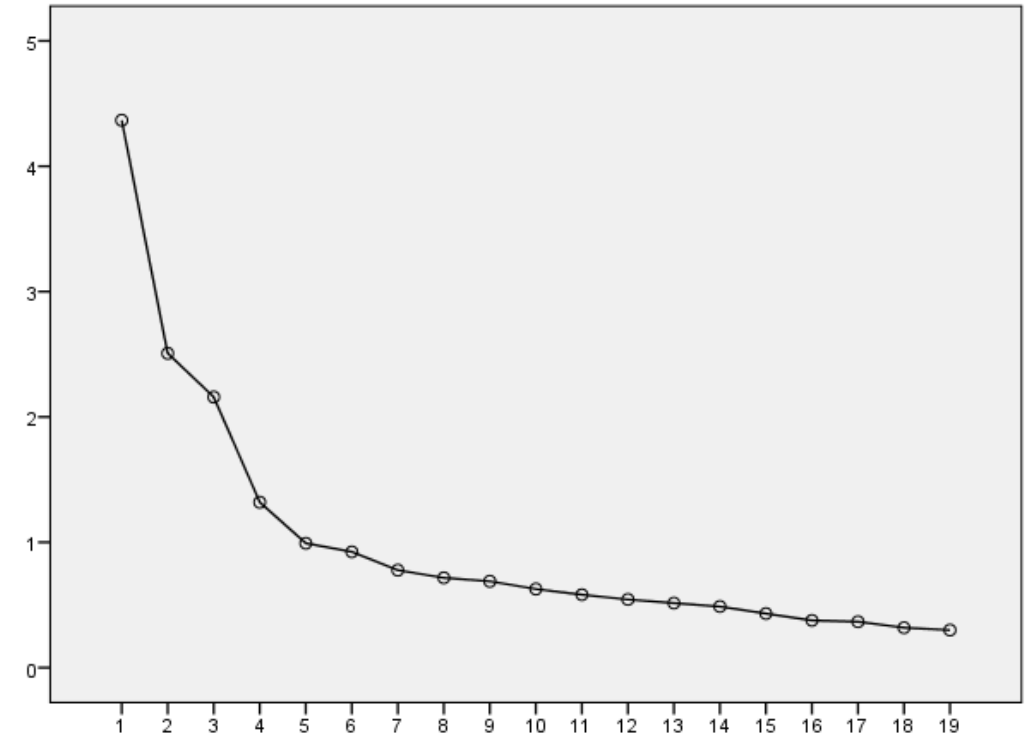

Şekil 1. Açımlayıcı Faktör Analizi Saçılım Grafiği

Saçılım grafiğine incelendiğinde öz-değeri 1'den büyük 4 faktörün olduğu görülmektedir. AFA sonucunda sanal zorbalıkla başa etme stratejileri ölçeğinin yapısının dört faktörlü olmasına karar verilmiştir. AFA sonucunda maddenin en düşük ortak faktör varyansı değerinin 0,440 olduğu bulunmuştur (bkz: Tablo 1). Ancak 4 maddenin faktör yüklerinin birden fazla faktör için 0,30' dan yüksek değer aldığı görülmüş ve varimax (25) döndürmesi yapılmıştır. Döndürme işleminin sonucunda ölçeğin 4 faktör ve 19 maddeden oluştuğu görülmüştür. 
Tablo 1. Sanal Zorbalık İle Başaçıma Stratejileri Ölçeği Açımlayıcı Faktör Analizi Sonuçları

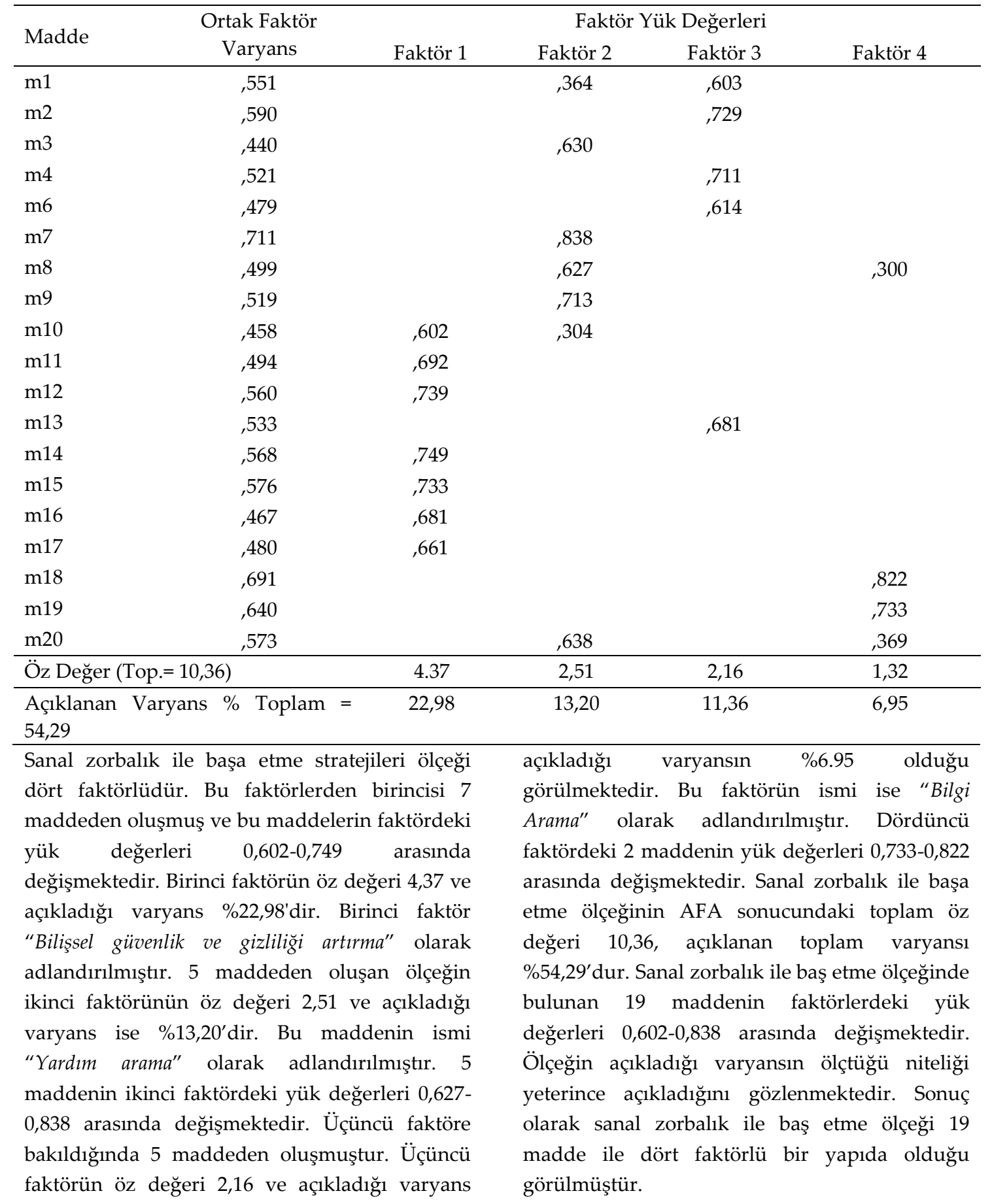
\%11,36 olup, ismi "Kaçınma ve görmezden gelme" olarak adlandırılmıştır. 5 maddenin üçüncü faktördeki yük değerleri 0,603-0,729 arasında değişmektedir. Ölçeğin dördüncü ve son faktörü 2 maddeden oluştuğu, öz değerinin 1.32 ve

\subsection{DFA'ya Yönelik Bulgular}

19 madde ve dört faktörden oluşan ölçeğin uyum indeksleri doğrulayıcı faktör analizi ile test edilmiştir. Doğrulayıcı faktör analizi, birinci düzen ve ikinci düzen analizleri ile 
gerçekleştirilmiştir. Sanal zorbalık ile baş etme stratejileri ölçeğinin birinci düzen doğrulayıcı faktör analizi sonucunda, uyum indeksleri $\chi^{2}=$ $349,39(\mathrm{sd}=148, \mathrm{p} .=.000), \chi^{2} / \mathrm{sd}=2,36 \mathrm{RMSEA}=$ $0.070, \mathrm{SRMR}=0,072, \mathrm{GFI}=0.88, \mathrm{AGFI}=0.85, \mathrm{CFI}=$ 0.92, $\mathrm{NFI}=0.86$ ve $\mathrm{NNFI}=0.90$ olarak bulunmuştur.

Yapılan ikinci düzen DFA sonucunda, ölçeği oluşturan dört faktörün sanal zorbalık ile başa çıkma stratejileri örtük değişkenini anlamlı bir biçimde açıklayıp açıklamadığına bakıldığında, tüm faktörlerin sanal zorbalık ile başa etme stratejileri örtük değişkenini anlamlı bir biçimde açıkladığı görülmüştür. Yapılan ikinci düzen doğrulayıcı faktör analizi modifikasyon önerileri doğrultusunda 10. ile 12., 12. ile 13. ve 23. ile 24. maddeler arasında modifikasyon yapilmasına karar verilmiştir. DFA işlemleri sonucunda her bir maddenin standart çözüm, $T$ ve $R^{2}$ değerleri Tablo 2'de yer almaktadır.

Tablo 2. DFA SÇ, T ve R2 Sonuçları

\begin{tabular}{llllllllllll}
\hline & SÇ & TD & $\mathrm{R}^{2}$ & & SÇ & TD & R $^{2}$ & & SÇ & TD & $\mathrm{R}^{2}$ \\
\hline M1 & .55 & - & .31 & M10 & .51 & - & .26 & M18 & .54 & - & .30 \\
M2 & .71 & 6.66 & .51 & M11 & .57 & 6.69 & .32 & M19 & .86 & 4.50 & .73 \\
M3 & .53 & - & .28 & M12 & .61 & 8.80 & .37 & M20 & .69 & 7.61 & .47 \\
M4 & .65 & 6.62 & .43 & M13 & .42 & 5.13 & .18 & F1 & .41 & 4.23 & .17 \\
M6 & .32 & 4.14 & .11 & M14 & .71 & 7.56 & .51 & F2 & .75 & 5.47 & .57 \\
M7 & .78 & 8.01 & .60 & M15 & .75 & 7.73 & .57 & F3 & .28 & 2.87 & .08 \\
M8 & .65 & 7.40 & .43 & M16 & .63 & 7.09 & .39 & F4 & .62 & 3.94 & .39 \\
M9 & .63 & 7.28 & .40 & M17 & .64 & 7.14 & .40 & & & & \\
\hline
\end{tabular}

$\mathrm{SÇ}=$ Standart Çözüm, TD= T Değerleri.

DFA'da dört faktörde yer alan maddelerin .32 ile .86 arasında standart çözüme sahip olduğu görülmüştür. Bunun yanında maddelerin .11 ile .73 arasında $\mathrm{R}^{2}$ değerine sahip olduğu bulunmuştur. Bu değerlerin yüksek çözüm değerleri olması nedeniyle tüm faktörlerdeki maddelerin, faktörleri için önemli olduğuna karar verilmiştir. Standart çözümlerden sonra faktörler ve maddeler arasındaki $t$ değerlerine bakılmıştır. Jöreskog ve Sörbom (1996) t değerleri ile ilgili kırmızı ok bulunmamasının tüm maddelerin .05 düzeyinde anlamlı olduğunu ifade etmektedir. $\mathrm{T}$ değerlerinde kırmızı ok bulunmaması tüm maddelerin .05 düzeyinde anlamlı olduğunu göstermiştir. Maddelerin 4.14 ile $8.80 \mathrm{t}$ değerlerine sahip olduğu bu değerlerin .01 düzeyinde de anlamlı olduğu ortaya çıkmıştır.

Yapılan analiz sonucunda, uyum indeksleri $\chi^{2}$ $(\mathrm{sd}=146, \quad \mathrm{p} .=.000) \quad=263.36, \quad \chi^{2} / \mathrm{sd}=1.80$ RMSEA=0.054, $\quad$ SRMR $=0.067, \quad$ GFI $=0.91$, AGFI $=0.88, \quad \mathrm{CFI}=0.95, \mathrm{NFI}=0.90$ ve $\mathrm{NNFI}=0.94$ olarak bulunmuştur. Modele yönelik elde edilen sonuçların değerlendirilmesinde SchermellehEngel, Moosbrugger ve Müller (2003) tarafından önerilen uyum indeks değerleri temel alınmış ve ölçeğin uyum indeksi değerleri incelendiğinde $\chi^{2} / \mathrm{sd}$, SRMR, CFI ve NNFI iyi uyumu, GFI, NFI ve RMSEA ise kabul edilebilir uyum değerine sahip olarak bulunmuştur. Ancak AGFI uyum indeksleri ise kabul edilebilir değerlerin altında bulunmuştur. Genel olarak dört faktörlü yapı kabul edilebilir uyum gösterecek değerlere sahip olarak nitelenebilir.

\subsection{Güvenirliğe Yönelik Bulgular}

Ölçeğin 19 maddesini ele alan Cronbach alfa iç tutarlılık katsayısı 0,750' dir. Ölçeğin alt faktörleri için iç tutarlılık güvenirlik değerleri sırasıyla Faktör 1 için iç tutarlılık 0,657; Faktör 2 için iç tutarlılık 0,762; Faktör 3 için iç tutarlılık 0,737 ve Faktör 4 için 0,635 olduğu tespit edilmiştir. İç tutarlılık güvenirlik değerlerinin 0,70 'e yakın ya da yüksek olduğu tespit edilerek ölçeğin güvenilir ve tutarlı olduğu söylenebilir.

\subsection{Sanal Zorbalıkla Başa Etme Ölçeği Kesim Noktaları}

Ölçek formundan alınan toplam puanlar homojen dağılıma sahip olma durumuna göre iki aşamalı kümeleme analizine tabi tutulmuştur. 
Kümeleme analizinde her seviyedeki kesim noktaları (cut-off) daha detaylı bir şekilde ortaya konabilmiştir. Kümeleme analizinde ölçekten alınacak toplam puanın, 19 - 47, 48 - 64, 65 - 95 şeklinde kümelenmesini uygun görmüştür. $\mathrm{Bu}$ yolla, baş etme stratejileri bilgisi düzeylerinin detaylı bir şekilde ölçülmesi mümkün olabilmektedir. Ölçekten 19 - 47 puan aralığ düşük, 48 - 64 puan aralığı orta ve 65 - 95 puan aralığı yüksek baş etme stratejileri bilgisi olarak ifade edilebilir.

\section{SONUÇ, TARTIŞMA VE ÖNERILLER}

Teknolojinin bireylere sağladığı birçok kolaylık nedeniyle günümüzde bireyler tarafından yaygın bir şekilde kullanılmakta, bundan sonraki süreçte de sağladığı kolaylığa ve teknolojik okuryazarlığın artmasına bağlı olarak daha da yaygın olarak kullanılacağı düşünülmektedir. Bilgi ve iletişim teknolojileri, bireylere sağladığı birçok kolaylığa rağmen bu araçların bazı bireyler tarafından başkalarına zarar vermek amacıyla kullanmaya başlamasıyla birlikte günümüzde bireyler arasında sanal zorbalık denilen bir saldırganlık türü görülmeye başlanmiştır.

Alan yazında farklı ülkelerde yapılan çalışmalar incelendiğinde özellikle okullarda öğrenciler arasında yaşanan bu sorunun hiçte küçümsenmeyecek boyutlarda olduğu ve bu tür olayların bireyleri psikolojik, akademik ve sosyal açıdan olumsuz şekilde etkilediği yapılan çalışmalar incelendiğinde görülmektedir.

Sanal zorbalık olaylarıyla bireylerin nasıl baş ettiklerini belirlemek ve uygun baş etme stratejileri konusunda yeterli beceriye sahip olmayan bireylere uygun baş etme stratejileri konusunda bilgi vermek daha sonraki süreçte yapılacak önleme çalışmalarında önemli bir yere sahip olduğu dikkate alındığında bireylerin sanal zorbalıkla baş etme stratejilerini belirlemeye ihtiyaç vardır. Bu nedenle liselerde eğitim öğretim süreci devam eden öğrencilerin sanal zorbalıkla başa etme düzeylerini belirlemeye yönelik bir ölçme aracını geliştirmeye ihtiyaç duyulmuştur.

Yapılan bu çalışmada, lise öğrencilerinin sanal zorbalıkla baş etme ölçeği geliştirilmiş ve ölçeğin psikometrik özellikleri incelenmiştir. Ölçeğin geçerlik çalışmaları için kapsam, görünüş, faktöriyel ve yapı geçerliğine bakılmıştır. Kapsam ve görünüş geçerliği için uzman görüşü alınmıştır. Ölçeğin faktöriyel geçerliği için DFA ve AFA yapılmıştır. Ölçeğin güvenirliğine Cronbach alfa iç tutarlılık ve kompozit güvenirlik katsayıları ile bakılmıştır. Geliştirilen sanal zorbalıkla baş etme Ölçeği 19 madde ve dört faktörden oluşmaktadır.

Dört faktörden oluşan sanal zorbalıkla baş etme ölçeğinin birinci faktörü 7 maddeden oluşmuş ve bu maddelerin faktördeki yük değerleri 0,6020,749 arasında değişmektedir. Birinci faktörün öz değeri 4,37 ve açıkladığı varyans \%22,98'dir. Bu faktörün iç tutarlılık kat sayısı 0,657 olarak belirlenmiştir. Ölçeğin ikinci faktörü 5 maddeden oluşmaktadır. İkinci faktörünün öz değeri 2,51 ve açıkladığı varyans ise \%13,20'dir. İkinci faktörün iç tutarlık katsayısı 0,762 olarak tespit edilmiştir. Ölçeğin faktörüne bakıldığında 5 maddeden oluştuğu görülmektedir. Üçüncü faktörün öz değeri 2,16 ve açıkladığı varyans \%11,36 dır. Üçüncü faktörün iç tutarlılık kat sayısı 0,737 dır. Dördüncü faktör 2 maddeden oluşmaktadır. maddelerin yük değerleri 0,7330,822 arasında değişmektedir. Bu faktörün öz değeri 1.32 ve açıkladığı varyans \%6.95'tir. Bu faktörün iç tutarlık kat sayısı 0,635'dir.

Ölçek geliştirme kapsamında yapılan psikometrik çalışmalar sonucunda elde edilen veriler dikkate alındığında ölçeğin lise öğrencilerinin sanal zorbalıkla baş etme düzeylerinin belirlenmesinde geçerli ve güvenilir bir araç olduğu ve bu amaç doğrultusunda kullanılabileceği savunulabilir. Geliştirilen bu ölçek lise öğrencilerine yönelik olarak geliştirilmiştir. Ölçeğin farklı yaş gruplarına uygulanabilmesi için tekrardan geçerlilik güvenirlik çalışması yapılması önerilmektedir. 


\section{Kaynakça}

Arıcak, O. T., Kınay, H. ve Tanrıkulu, T. (2012). Siber Zorbalık Ölçeği'nin ilk psikometrik bulguları. Hasan Âli Yücel Ĕ̆itim Fakültesi Dergisi, 9(1), 101-114.

Arıcak, O. T. (2011). Siber Zorbalık: Gençlerimizi Bekleyen Yeni Tehlike. Kariyer Penceresi, 6, 10-12.

Ayas, T (2011). Lise öğrencilerinin sanal zorba ve mağdur olma yayginlığı. XI. Ulusal Psikolojik Danışma ve Rehberlik Kongresi 3-5 Ekim 2011 İzmir

Ayas, T. (2014). Depresyon, anksiyete ve cinsiyet değişkenlerine göre sanal zorbalığa maruz kalma düzeylerinin yordanması. Online Journal Of Technology Addiction \& Cyberbullying 1, 1-17.

Ayas, T. \& Horzum, B. (2011). Exploring the Teachers' Cyber Bullying Perception in terms of Various Variables. International Online Journal of Educational Sciences, 3(2), 619-640.

Ayas, T. ve Horzum, M.B. (2012). İlköğretim öğrencilerinin sanal zorba ve mağdur olma durumu. Ilköğretim Online, 11(2), 369-380

Ayas,T., Aydın, F., \& Horzum, M. B. (2015). Cyberbullying Awareness Scale: A Validity and Realiablity Study. Online Journal of Technology Addiction \& Cyberbullying, 2(4).

Batmaz, M. ve Ayas, T (2013) İlköğretim ikinci kademedeki öğrencilerin psikolojik belirtilere göre sanal zorbalık düzeylerinin yordanması. Sakarya University Journal of Education, 3, 43-53

Belsey, B. (2008). Cyberbullying. Retrieved August 03, 2008, from, http://www.cyberbullying.org

Beran, T., \& Li, Q. (2005). Cyber-harassment: A study of a new method for an old behavior. Journal of Educational Computing Research, 32(3), 265-277.

Broll, R. (2014). Collaborative responses to cyberbullying: preventing and responding to cyberbullying through nodes and clusters. Policing and society, 1-18

Bryce,J., Klang, M . (2009) Young people is disclosure of personal information and Technical Report .14,160-166

Bulut, Y., \& Alc1, B. (2014). Cyberbullying Among Secondary School Students.

Burgess-Proctor, A., Hinduja, S. \& Patchin, J.W. (2010). Victimization of adolescent girls. Cyberbullying Research Center.

Campbell, M.A. (2005). Cyberbullying: An old problem in a new guise? Australian Journal of Guidance and Counseling, 15(1), 68-76.

Çelen, F. K., Çelik, A. ve Seferoğlu, S. S. (2011). Çocukların İnternet kullanımları ve onları bekleyen çevrim-içi riskler. Akademik Bilişim, 2-4.

Dursun, Ö. Ö., \& Akbulut, Y. (2010). Investigation of cyberbullying victimization and communication styles in a hybrid learning environment. Paper presented at IODL \& ICEM International Joint Conference and Media Days, Eskisehir, Turkey.

Dredge, R., John, G. ve Garcia, X. P. 2014. Cyberbullying in social networking sites: An adolescent victim's perspective. Computers in Human Behavior. 36, 13-20.

Eroğlu, Y. (2011). Koşullu öz-değer riskli internet davranışları ve siber zorbalık/mağduriyet arasındaki ilişkinin incelenmesi. Yayınlanmamış yüksek lisans çalışması, Eğitim Bilimleri Enstitüsü, Sakarya Üniversitesi, Sakarya.

Frisén, A., Berne, S., \& Marin, L. (2014). Swedish pupils' suggested coping strategies if cyberbullied: Differences related to age and gender. Scandinavian journal of psychology, 55(6), 578-584.

Hinduja, S., \& Patchin, J. W. (2008). Cyberbullying: An exploratory analysis of factors related to off ending and victimization. Deviant behavior, 29(2), 129-156.

Hinduja, S., \& Patchin, J. W. (2010). Bullying, cyberbullying, and suicide. Archives of Suicide Research, 14(3), 206-221.

Jones, L. M., Mitchell, K. J., \& Finkelhor, D. (2013). Online harassment in context: Trends from three Youth Internet Safety Surveys (2000, 2005, 2010). Psychology of Violence, 3(1), 53.

Juvonen, J. and E.F. Gross (2008). 'Extending the School Grounds? Bullying Experiences in Cyberspace', Journal of School Health 78(9): 496-505.

Kowalski, R.M. \& Limber, S.P. (2007). Electronic bullying among middle school students. Journal of Adolescent Health, 41, 22-30. 
Lenhart, A., Madden, M., Macgill, A.R., \& Smith, A. (2007). Teens and social media: The use of social media gains a greater foothold in teen life as they embrace the conversational nature of interactive online media. Pew Internet \& American Life Project.

Li, Q. (2006) Cyberbullying in schools : A research of gender differences. School Pyschology International. $27,157-170$

Murphy, J. J. (2008). Solution-focused counseling in schools (2nd Ed.). Alexandria VA: American Counseling Association.

O'Brien, N., \& Moules, T. (2013). Not sticks and stones but tweets and texts: findings from a national cyberbullying project. Pastoral care in education, 31(1), 53-65.

Olweus, D. (1999). Sweden. In P. K. Smith, Y. Morita, J. Junger-Tas, D. Olweus, R. Catalano, ve P. Slee (Eds.), The nature of school bullying: A cross-national perspective. London and New York: Routledge.

Olweus, D. (1995). Bullying or peer abuse at school: Facts and intervention. Current Directions in Psychological Science, 4, 196-200.

Patchin, J. W. \& Hinduja, S. (2006). Bullies move beyond the school yard: A preliminary look at cyber bullying. Youth Violence and Juvenile Justice, 4(2), 148-169

Peker, A., Özhan, M. B. ve Eroğlu, Y. (2015). Development of the Scale on Coping with Cyber Bullying towards Adolescents Ergenlere Yönelik Siber Zorbalıkla Başa Çıkma Ölçeği'nin geliştirilmesi. International Journal of Human Sciences, 12(1), 569-581.

Raskauskas, J. \& Stoltz, A. D. 2007. Involvement in traditional and electronic bullying among adolescents. Developmental Psychology, 43,564-575.

Raskauskas, J \& Huynh, A. (2015). The process of coping with cyberbullying: A systematic review. Aggression and violent behavior, 23, 118-125.

Scaglione, J., \& Scaglione, A. R. (2006). Bully-proofing children: A practical, hands- on guide to stop bullying. Lanham, MD: Rowman \& Littlefield Education.

Smith, P. K., Mahdavi, J., Carvalho, M. ve Tippett, N. (2006). An investigation into cyberbullying, its forms, awareness, and impact, and the relationship between age and gender in cyberbullying. London: Goldsmith College, University of London.

Syts, Y. (2004). Beyond the schoolyard: Examining electronic bullying among Canadian youth. Unpublished Master Thesis, Carleton University, Ottawa, Ontario.

Şahin, M., Aydın, B. \& Sarı, S. V. (2012) Cyberbullying, cyber victimization and psychological symptoms : A study in adolescent. C.U. Faculty of Education Journal, 41(1), 53 -59

Vandebosch, H., Van Cleemput, K., Mortelmans, D., \& Walrave, M. (2006). Cyberbullying among youngsters in Flanders. Retrieved May 11, 2010 from http://www.viwta.be/files/cyberbullying\%20executive\%20overwiev.pdf.

Völlink, T., Bolman, C. A., Dehue, F., \& Jacobs, N. C. (2013). Coping with cyberbullying: Differences between victims, bully-victims and children not involved in bullying. Journal of community $\mathcal{E}$ applied social psychology, 23(1), 7-24.

Wachs, S., Wolf, K. D., \& Pan, C. C. (2012). Cybergrooming: Risk factors, coping strategies and associations with cyberbullying. Psicothema, 24(4), 628-633.

Willard, N. (2007). Cyberbullying and cyberthreats. U.S.A. Research Pres.

Wolak, J., Mitchell, K.J., Finkelhor, D. (2007). Does online harassment constitute bullying? An exploration of online harassment by known peers and online-only contacts. Journal of Adolescent Health, 41, 51-58.

Worthen,M.R. (2007) Education policy implications from the expert panel on elec- tronic media and youth violence. Journal of Adolescent Health, 41, 64-65

Yaman, E., Eroğlu, Y., ve Peker, A. (2011). Başa çıkma stratejileri ile okul zorbalı̆̆ı ve siber zorbalık.

Ybarra, M. L. (2004). Linkages between depressive symptomatology and Internet harassment among young regular Internet users. CyberPsychology E Behavior, 7, 247 - 257.

Ybarra, M. L., \& Mitchell, J. K. (2004). Online aggressor/targets, aggressors, and targets: A comparison of associated youth characteristics. Journal of Child Psychology and Psychiatry, 45, 1308-1316. 


\section{EXTENDED SUMMARY}

\section{Introduction}

Although information and communication technologies provide new, comfortable and useful places, they cause some problems like cyberbullying and cyber victimization (Li, 2006).

Technological developments provide some opportunities like discovering the world, learning and having fun but they also cause the easily access to some web sites that are related with sex, violence, substance use (Peker, Eroğlu and Ada, 2012). Technological developments catch attention of people via media but also they bring new problems like cyber victimization and cyberbullying.

Some researches supported that cyber victimization cause unjust suffering that a person or a group who are subjected to harmful behaviors via information and communication technologies and they have both financial and emotional damage (Ayas and Horzum, 2012). People who are cyber victims reported that their experiences were very stressful (Patchin and Hinduja, 2006). Cyberbullying is defined as using information and communication technologies repeatedly to harm people intentionally. It can be said that cyber bullying harm people via SMS (Short Message Service), taking photo and video with mobile phone camera, harassing people via mobile phone, chat rooms, e-mail, web sites.

Campbell supported that cyberbullying has been common in all over the world especially in England, ABD, Canada, and Japan (Campbell, 2005). Furthermore, according to the results of a study, cyberbullying and cyber victimization have negative effects on psychosocial development and academic achievement of youths (Baran and Li, 2005). Moreover, Sahin, Aydin and Sarı also found that cyberbullying damages personal, social, emotional and psychological development of teenagers (Şahin, Aydin and Sarı, 2012).

Worthen (2007) supported that preventing and coping programs should be developed to protect students from negative effects of cyberbullying. Instead of waiting the progress of problem, trying to prevent the problems at the beginning will be helpful to protect students from cyber bullying. Prevention is better than acting after the events because it will be helpful to protect students from emotional and economical effects of bullying. Furthermore, it can be said that getting information about the features of cyberbullying will be helpful and effective to develop prevention and coping programs. Besides them, Li (2006) supported that preventing and coping programs should be organized with participation of school, family and society.

Psychologists and consultants in schools should develop awareness, prevention and intervention programs to deal with cyberbullying. They should behave as leaders to prevent cyberbullying and work together with families. Besides, students should learn how to use internet, computers and other communication tools confidentially and responsibly. Students also should know related sources and their addresses to apply if they need. Furthermore, parents do not have enough information about modern communication tools and they do not know technological developments (Dursun and Akbulut, 2010). So, parents cannot notice cyberbullying experiences of their children. Parents should improve themselves and they should communicate with their children clearly (Hinduja and Patchin, 2010). Parents should inform their children about how to use internet and other communication tools proper to their development levels. At the same time, they should restrict and control their children.

Beran and Li (2005) also supported that parents should improve themselves to have enough information about technological tools to control and train their children about internet and other technological tools. Most of the students reported that their parents do not have enough information about technology and computer. According to Kowalski and Limber (2007), $89 \%$ of the students use technologic tools better than their families, $18 \%$ of families also reported that they use technology very well. Worthen (2007) designed a study with students and it was found that $38 \%$ of the children reported that their families 
have enough information about technology. Besides, $12 \%$ of adolescents said that their families educate and give them information about negative effects of technology. This study is designed to develop a scale for determining coping strategies of students.

\section{Method}

Participants: 264 high school students from Sakarya participated to the study for exploratory factor analysis. 140 of them are ninth class $(53 \%)$ and 14 of them are $11^{\text {th }}$ class students. 129 of the participants $(48,9 \%)$ were female and 135 of them $(51,1 \%)$ were male. 277 high school students from Sakarya participated to second study that is confirmatory factor analysis. $135(48.7 \%)$ of the students studied in ninth class and $142(51.3 \%)$ of them in $10^{\text {th }}$ class. $136(49.1 \%)$ of the students were female, $141(50.9 \%)$ of them were male. The ages of the students were between 15 and 18.

\section{Data Collection Tools}

Coping Strategies for Cyberbullying Scale was developed by the researchers. During the scale development process first of all, the literature related with coping stratgies with cyberbullying was reviewed and item pool was created. According to the studies of Peker, Özhan ve Eroğlu (2015), Raskauskas ve Huynh (2015), Broll (2014), Frisén, Berne ve Marin (2014), Völlink, Bolman, Dehue ve Jacobs (2013), O'Brien ve Moules (2013), Wachs, Wolf ve Pan (2012) some items were corrected. There were 20 items in the item pool. 5 - Likert tScale was used.

\section{Procedure}

Factor analysis, construct validity, factor analysis and reliability analysis were applied. Confirmatory factor analysis and exploratory factor analysis were applied for factorial validity. Moreover, convergency was used for construct validity and Cronbach alpha and composite reliablity coefficient were used for distinguishing validity and reliability. At the end, valid and reliable coping with cyber bullying scale that has 19 items and 4 factors was developed.

\section{Results and Discussion}

The scale has 4 factors that first factor has 7 items and factor loadings of items are between 0,602 and 0,749 . The internal consistency coefficient of this factor is 0,657 . The second factor has 5 items and the internal consistency coefficient of this factor is 0,762 . Third factor has 5 items and the internal consistency coefficient of this factor is 0,737 . Fourth factor has 2 items and the internal consistency coefficient of this factor is 0,635 . 